\title{
Revisão integrativa dos estudos indexados sobre a Politica Nacional de Humanização na Biblioteca Virtual em Saúde - BVS
}

\author{
Integrative review of studies on linked to a National \\ Policy on Humanization Virtual Health Library - VHL
}

\author{
Revisión integral de los estudios indexados a cerca de la Política \\ Nacional sobre Humanización en la Biblioteca Virtual en Salud - BVS
}

Recebido: 03/09/2013

Aprovado: $12 / 01 / 2014$

\author{
Delvane José de Souza' \\ Divanice Contim $^{2}$ \\ Maria D'Innocenzo 3
}

O objetivo deste estudo foi identificar aspectos da implantação da Política Nacional de Humanização - PNH na base de dados da Biblioteca Virtual em Saúde - BIREME, no período de 2004 a 2012. Foi realizada uma revisão integrativa da literatura, que possibilitou identificar 186 estudos, sendo selecionadas 26 pesquisas que relacionavam as estratégias de implantação dos dispositivos; impactos na gestão e formas de produção do cuidado e aspectos relacionais entre usuários, trabalhadores e gestores. As diretrizes da PNH garantem a participação dos usuários e trabalhadores na gestão do cuidado; oferece uma série de estratégias de enfrentamento aos problemas do setor saúde e direciona as políticas de saúde em consonância com os princípios do Sistema Único de Saúde.

Descritores: Humanização da Assistência; Políticas Públicas; Revisão.

The aim of this study was to identify aspects of the implementation of the National Policy of Humanization (NPH) in the Brazil, in the database of the Virtual Health Library - BIREME in the period 2004-2012. It performed an integrative literature review, which enabled the identification of 186 studies, 26 studies were selected that related deployment strategies of devices; impacts on management and production forms of care and relational aspects between users, workers and managers. The guidelines NPH ensure the participation of users and workers in care management; offers a range of coping strategies to the problems of the health sector and directs health policies in line with the principles of the Health System in Brazil.

Descriptors: Humanization of Assistance; Public Policies; Review.

El objetivo de este estudio fue identificar los aspectos de la aplicación de la Política Nacional de Humanización (PNH) en el Brasil en la base de datos de la Biblioteca Virtual en Salud - BIREME en el período 2004-2012. Se realizó una revisión integradora de la literatura, lo que permitió la identificación de 186 estudios, en la cual se seleccionaron 26 estudios a cerca de las estrategias de implementación relacionados con los dispositivos, los impactos sobre las formas de gestión y producción de la atención y los aspectos relacionales entre los usuarios, los trabajadores y los directivos. La PNH garantiza directrices en la participación de los usuarios y de los trabajadores en la gestión de la atención, ofrece una gama de estrategias de afrontamiento de los problemas del sector de la salud y dirige las políticas de salud de acuerdo con los principios del Sistema de Salud brasileño.

Descriptores: Humanización de la Atención; Políticas Públicas; Revisión.

\footnotetext{
${ }^{1}$ Enfermeiro. Mestre em Promoção de Saúde. Doutorando em Enfermagem pela Universidade Federal de São Paulo-UNIFESP. Enfermeiro do Centro de Graduação em Enfermagem da Universidade Federal do Triângulo Mineiro-UFTM. delvane.jose@gmail.com

2 Enfermeira. Doutora em Ciências. Professora Adjunta II do Departamento de Enfermagem em Atenção Hospitalar da UFTM. d.contim@uol.com.br

${ }^{3}$ Enfermeira. Doutora em Enfermagem. Professora Associada da UNIFESP.
} 


\section{INTRODUÇÃO}

$\mathrm{N}$ o contexto dos serviços de saúde relativo à ocorrência de baixo investimento e queixas dos trabalhadores e usuários quanto ao desrespeito dos seus direitos, o Ministério da Saúde propôs em 2003 a Política Nacional de Humanização da Atenção e Gestão (PNH) ${ }^{1}$.

Dentre as prioridades do $\mathrm{PNH}$ destacam-se ações para a melhoria do atendimento do usuário, como a redução de filas e do tempo de espera para o atendimento, ambiente acolhedor e resolutivo baseado em critérios de risco. A melhoria do atendimento envolve a estrutura dos serviços com a territorialização, ao processo de gestão participativa e a educação permanente dos trabalhadores, sustentada pela transversalidade indissociabilidade e pela autonomia dos sujeitos e coletivos, implicando atitudes de corresponsabilidade nos processos de gerir e de cuidar ${ }^{2}$.

Os estudos sobre essa temática relacionada à gestão dos serviços de saúde têm demonstrado varias implicações como a compreensão do que venha a ser "humanização" e o desconhecimento da PNH por parte de profissionais e usuários, dificultando a implantação e operacionalização dessa política nos equipamentos de atenção a saúde. Contudo, o tema vem ocupando uma posição de destaque na agenda de discussões dos processos de trabalho e gestão em saúde no Brasil $^{3,4}$.

A fim de cooperar com um melhor entendimento das proposições desta política, a realização desta pesquisa teve como objetivo caracterizar a produção cientifica sobre aspectos da implantação desta política na base de dados da Biblioteca Virtual em Saúde - BIREME, no período de 2004 a 2012. Para guiar a pesquisa, formulou-se a seguinte pergunta: o que diz a literatura cientifica brasileira sobre a $\mathrm{PNH}$ ?

\section{MÉTODO}

Trata-se de uma Revisão Integrativa (RI) sobre a implantação das ações propostas pela PNH na Atenção e Gestão e de seus indicadores em vigor desde 2004. A pesquisa foi desenvolvida em seis etapas: identificação do tema, estabelecimento de critérios de inclusão e exclusão, definição de informações a serem extraídas e avaliação dos estudos, interpretação dos resultados e síntese do conhecimento ${ }^{5}$. Inicialmente formulou-se a questão de pesquisa sobre a PNH Brasil: quais foram os estudos publicados em periódicos online no período de 2004 a 2012, no campo da humanização da assistência?

o levantamento bibliográfico foi realizado nas bases de dados eletrônicas; Literatura Latino-Americana e do Caribe em Ciências de Saúde (LILACS), Base de Dados de Enfermagem (BDENF), Literatura Internacional em Ciências da Saúde (MEDLINE) e Scientific Eletronic Library Online (SciELO), no período de 2004 a 2012. A escolha dessas bases de dados se deu em virtude de sua abrangência nacional e internacional consideradas referências na produção do conhecimento na área de saúde e por permitir acesso dos dados atualizados.

Os critérios de inclusão estabelecidos para orientar a busca foram: estudos na integra disponíveis on-line sobre a temática $\mathrm{PNH}$, relacionados à implantação, impactos, avaliação publicados em periódicos de língua portuguesa, inglesa e espanhola.

A busca foi realizada no mês de outubro de 2012, orientada pelos descritores controlados e pesquisados nos Descritores em Ciência da Saúde (DeCS/Bireme): humanização e humanização da assistência e as palavras-chaves empregadas nos idiomas português ou inglês, visando abranger o objeto de estudo.

Para a coleta de dados foi utilizado um instrumento com o intuito de identificar: autores, título, categoria profissional do primeiro autor; resumo da pesquisa e endereço eletrônico da publicação. Este instrumento permitiu a sistematização dos dados que, posteriormente, foram 
organizados e catalogados em ordem numérica crescente por ano de publicação.

Tabela 1. Artigos publicados sobre humanização da assistência, por periódico e ano, no período de 2004 a 2012. Brasil, 2013.

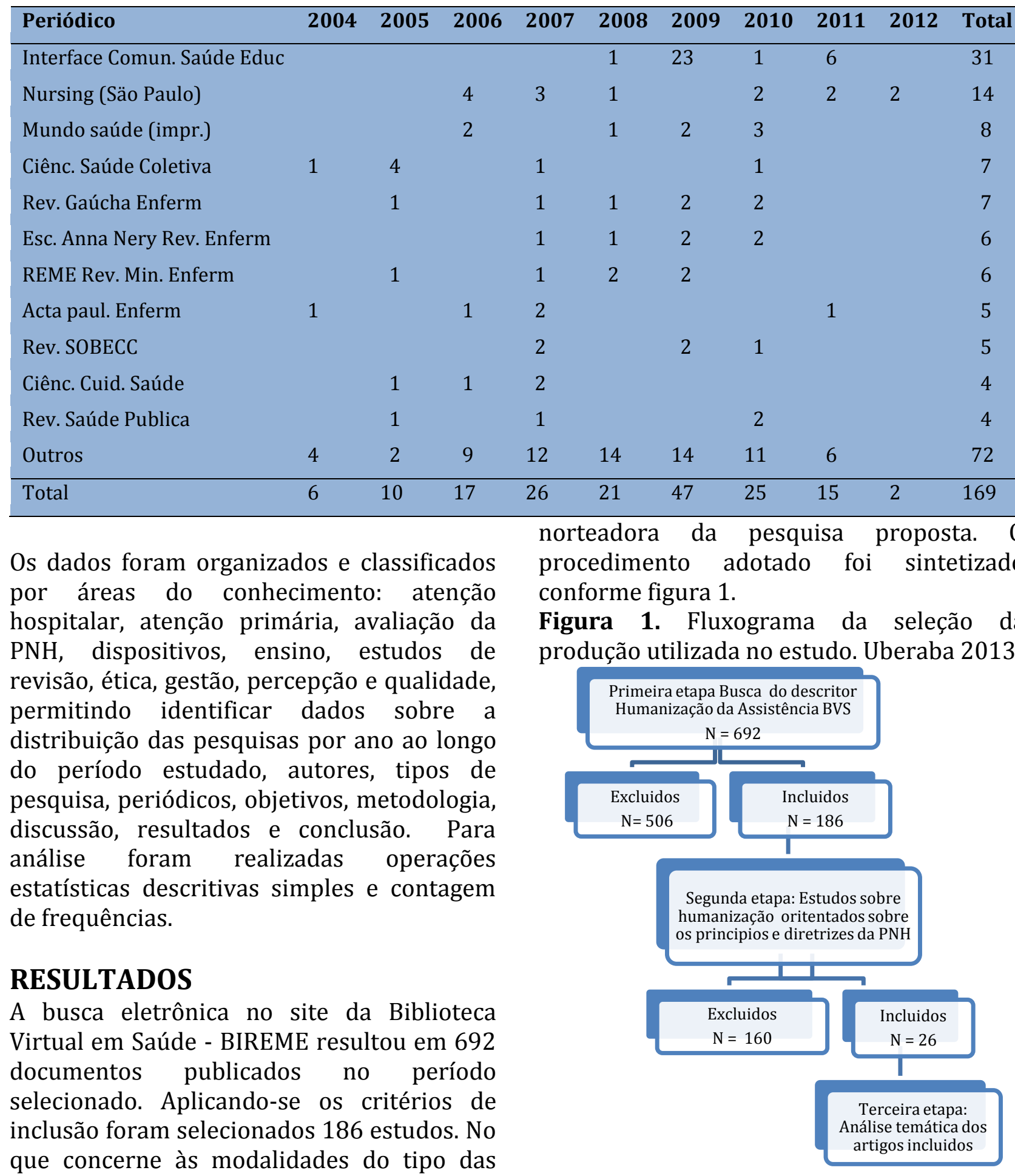

produções 169 (90,86\%) foram artigos de periódicos, $8(4,30 \%)$ teses, $7(3,77 \%)$ dissertações e $2(1,07 \%)$ livros.

A partir dos resultados obtidos realizou-se a leitura da produção, no intuito de verificar a adequação à questão 
2009, com um ligeiro decréscimo em 2010 e 2011.

Em relação à área de formação profissional dos autores das publicações, predominou os profissionais da área de Enfermagem (54\%), seguidos da área médica (14\%), Psicologia (12\%), Odontologia e Psicologia (4\%). E por fim, 21\% ficaram distribuídos em várias outras áreas (Fonoaudiologia, Nutrição, Letras, Pedagogia, Musicoterapia, Educação Física e Farmácia).

\section{DISCUSSÃO}

\section{Estratégias de implantação dos dispositivos da PNH}

Conforme os estudos apresentados no Quadro 1, A PNH reconhece que os estados, municípios e serviços de saúde estão
Em seguida procedeu-se a leitura e análise das informações, enumerando-se os diferentes aspectos da PNH. Dos 169 artigos, selecionou-se 26 que atendiam na integra os objetivos da pesquisa. Nesta etapa evidenciaram-se três categorias descritas nos Quadros 1, 2 e 3: estratégias de implantação dos dispositivos da PNH, Impactos da PNH na gestão e formas de produção do cuidado em saúde e percepções sob a humanização e aspectos relacionais entre usuários, trabalhadores e gestores.

implantando práticas de humanização nas ações de atenção e gestão com bons resultados, o que contribui para a legitimação do SUS como política pública6.

Quadro 1. Publicações selecionadas com ênfase nas estratégias de implantação dos dispositivos da PNH. Brasil, 2013.

\begin{tabular}{|c|c|}
\hline Publicações selecionadas & Autores \\
\hline $\begin{array}{l}\text { Contratos internos de gestão no contexto da Polít } \\
\text { experimentando uma metodologia no referencial da c }\end{array}$ & $\begin{array}{l}\text { Santos } \\
2009\end{array}$ \\
\hline $\begin{array}{l}\text { Das Práticas espontâneas à "receita" de Humanização: um estudo sobre a } \\
\text { Implementação da Política Nacional de Humanização em um Hospital do } \\
\text { Rio de Janeiro. }\end{array}$ & $\operatorname{Lima}^{6} / 2007$ \\
\hline $\begin{array}{l}\text { Acolhimento aos usuários: uma revisão sistemática do atendimento no } \\
\text { Sistema Único de Saúde }\end{array}$ & $\begin{array}{l}\text { Carvalho, Marsicano,Carvalho, } \\
\text { Sales-Peres, Bastos e Sales- } \\
\text { Peres } 7 \text { / 2008 }\end{array}$ \\
\hline $\begin{array}{l}\text { Os processos de formação na Política Nacional de Hun } \\
\text { experiência de um curso para gestores e trabalhadores da at } \\
\text { em saúde }\end{array}$ & $\begin{array}{l}\text { Guedes, Pitombo e } \text { Barros }^{8} / \\
2009\end{array}$ \\
\hline $\begin{array}{l}\text { A educação a distância como redes de fomento às rede de cuidado em } \\
\text { saúde }\end{array}$ & Paulon e Carneiro ${ }^{9}$ \\
\hline $\begin{array}{l}\text { Trabalho em saúde e a implantação do acolhimento a atenção primária à } \\
\text { saúde: afeto, empatia ou alteridade? }\end{array}$ & $\begin{array}{l}\text { Scholze, Duarte Junior e Silva }{ }^{10} / \\
2009\end{array}$ \\
\hline $\begin{array}{l}\text { É possível humanizar a Medicina? Reflexões a propósito do uso do Cinema } \\
\text { na Educação Médica }\end{array}$ & González Blasco ${ }^{11} / 2010$ \\
\hline Classificação de risco na emergência: avaliação da equipe de enfermagem & $\begin{array}{l}\text { Nascimento, Hilsendeger, Neth, } \\
\text { Belaver e Bertoncello }{ }^{12} / 2011\end{array}$ \\
\hline $\begin{array}{l}\text { A musicoterapia na sala de espera de uma unidade básica de saúde: } \\
\text { assistência, autonomia e pragmatismo. }\end{array}$ & $\begin{array}{l}\text { Pimentel, Barbosa e } \text { Chagas }^{13} / \\
2011\end{array}$ \\
\hline $\begin{array}{l}\text { A responsabilidade socia } \\
\text { em saúde }\end{array}$ & $\begin{array}{l}\text { Trentini, Paim e } \text { Vásquez }^{14} / \\
2011\end{array}$ \\
\hline
\end{tabular}

A humanização dos serviços de saúde não se reduz a uma política governamental, mas uma experiência que se constrói a partir das experiências concretas do SUS e de suas diretrizes que influenciam os modos de gerir e fazer os processos de trabalho no âmbito dos serviços de saúde Para alcançar os objetivos planejados, a PNH oferta diversos dispositivos, entendidos com tecnologias ou modos de organizar a humanização $0^{1,9}$. 
0 acolhimento com classificação de risco surge como um desafio de superar as dificuldades de emergência, priorizado o atendimento imediato dos casos de maior gravidade. A implantação deste dispositivo evidenciou uma maior segurança para os profissionais desenvolverem suas práticas e maior atenção aos pacientes com risco imediato, bem como uma forma de organizar o trabalho nas unidades, em consonância com os princípios do SUS. Essa ferramenta busca reduzir os níveis de insatisfação de usuários e profissionais, agilizando a prestação do serviço, identificando as prioridades e, proporcionando a continuidade de tratamento do usuário ${ }^{3,15}$.

A inclusão dos trabalhadores na viabilização de um projeto de humanização é uma forma de olhar para a diversidade cultural e empática numa perspectiva de instrumentalizar o trabalhador de saúde para desenvolver o acolhimento, sem deixar de garantir sua própria humanização ${ }^{10}$.

A inclusão de estratégias como a musicoterapia foi utilizada como forma de acolhimento na sala de espera, permitindo aos usuários expressarem suas queixas quanto ao atraso no atendimento médico, bem como trabalhar as conexões de símbolos, sentimentos e histórias, permeando questões subjetivas da vivência e permitindo que fossem assistidos ${ }^{13}$. Nesse contexto os profissionais interagem como num ambiente harmonioso e mais prédispostos para o trabalho.

Foi relatado o uso do cinema como recurso educacional para refletir sobre a humanização na medicina, resgatando o sentido humanístico da profissão médica. Dentre os princípios da $\mathrm{PNH}^{11}$ valorizou-se que estes se destinam a amplificar a abrangência do "modo de fazer" humanizado em saúde, integrando novos atores aos processos de formação-intervenção, calçados nos princípios da inseparabilidade entre formar e intervir; foco no aprender fazendo, formação descentralizada, baseada nas experiências e atores locais e; avaliação formativa com estimulo a analisadores locais ${ }^{1,11}$.
A educação à distância (EAD) utilizada como estratégia de capacitação para preparar apoiadores institucionais da Humanização da Atenção e Gestão do SUS foi considerada benéfica, pois esta forma de ensino tem a flexibilidade em relação ao tempo e ritmo de aprendizado, associado a uma maior comunicação entre os participantes, democratizando os espaços de ensino e gestão ${ }^{9}$.

A experiência de formação de apoiadores institucionais da $\mathrm{PNH}$ voltado para gestores e trabalhadores da atenção básica num município no estado do Rio de Janeiro foi baseada no referencial metodológico "formação-intervenção". Os apoiadores institucionais atuam como multiplicadores nos processos de mudança das organizações, articulando conceitos e tecnologias advindas da análise institucional da gestão e dos modos de fazer preconizados pela $\mathrm{PNH}^{8}$.

Quanto às dificuldades de implantação dos dispositivos da PNH, relacionada aos profissionais foi encontrado estudos que discutem a resistência do corpo médico, a exclusão dos trabalhadores dos processos decisórios. Agrega-se a essa dificuldades questões relativas à precarização do trabalho em saúde como: vínculos temporários, empregabilidade, condições de trabalho, falta de compaixão na relação profissional/usuário, falta de ações educativas e capacitação, desconhecimento da PNH e seus dispositivos, rotinas rígidas e descaso dos governantes, influencia da gestão clássica no modelo de gestão do trabalho, resultando em insatisfação e comunicação ineficaz. Como resultados são raros aqueles que reconhecem os progressos nos serviços de saúde como um direito de

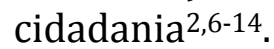

\section{Impactos da PNH na gestão e formas de produção do cuidado em saúde}

Os estudos inseridos nesta categoria indicam que o modelo de gestão clássica e hierárquica exerce forte influencia na organização dos serviços de saúde. Esse tipo de organização nem sempre garante que as Na lógica da PNH a gestão dos serviços é 
práticas dos diversos trabalhadores se complementem ou que as ações sejam eficazes. Como é observado a desmotivação dos trabalhadores e pouca participação dos usuários no processo de produção em saúde ${ }^{3,15-23}$. As publicações desta categoria estão no Quadro 2.

Quadro 2. Publicações selecionadas com ênfase no impacto da Política Nacional de Humanização da Atenção e Gestão nos serviços de Saúde. Brasil, 2013.

\begin{tabular}{|c|c|}
\hline \multicolumn{2}{|c|}{$\begin{array}{l}\text { Categoria } 2 \text { - Impactos da PNH na gestão e } \\
\text { formas de produção do cuidado em saúde }\end{array}$} \\
\hline Publicações selecionadas & Autores \\
\hline $\begin{array}{l}\text { Gestão do processo de trabalho da } \\
\text { enfermagem em uma enfermaria } \\
\text { pediátrica de média e alta } \\
\text { complexidade: uma discussão sobre } \\
\text { cogestão e humanização }\end{array}$ & $\begin{array}{l}\text { Alves, } \\
\text { Deslandes e } \\
\text { Mitre }^{3} \text { / } \\
2011\end{array}$ \\
\hline $\begin{array}{l}\text { Humanização e autogestão em uma } \\
\text { unidade básica de saúde }\end{array}$ & $\begin{array}{l}\text { Silveira e } \\
\text { Baldacci }^{15} / \\
2006\end{array}$ \\
\hline $\begin{array}{l}\text { O reencantamento do concreto e as } \\
\text { apostas nas mudanças nos modelos } \\
\text { de atenção e de gestão do SUS (o } \\
\text { caso do Instituto Hospitalar General } \\
\text { Edson Ramalho/João } \\
\text { Pessoa/Paraíba) } \\
\end{array}$ & $\begin{array}{l}\text { Coêlho }{ }^{16} / \\
2006\end{array}$ \\
\hline $\begin{array}{l}\text { O produto do serviço de enfermagem } \\
\text { na perspectiva da gerencia de } \\
\text { qualidade. }\end{array}$ & $\begin{array}{l}\text { Backes, } \\
\text { Silva, } \\
\text { Siqueira e } \\
\text { Erdmann17\% } \\
2007 \\
\end{array}$ \\
\hline $\begin{array}{l}\text { Perspectivas da avaliação na Política } \\
\text { Nacional de Humanização em Saúde: } \\
\text { aspectos conceituais e metodológicos }\end{array}$ & $\begin{array}{l}\text { Santos- } \\
\text { Filho }^{18 /} \\
2007\end{array}$ \\
\hline $\begin{array}{l}\text { Gestão participativa e } \\
\text { corresponsabilidade em saúde: } \\
\text { limites e possibilidades no âmbito da } \\
\text { Estratégia de Saúde da Família }\end{array}$ & $\begin{array}{l}\text { Trad e } \\
\text { Esperidião }^{1} \\
9 / 2009\end{array}$ \\
\hline $\begin{array}{l}\text { Aspectos Humanos na gestão } \\
\text { hospitalar }\end{array}$ & $\begin{array}{l}\text { Pinochet e } \\
\text { Galvão }{ }^{20} / \\
2010\end{array}$ \\
\hline 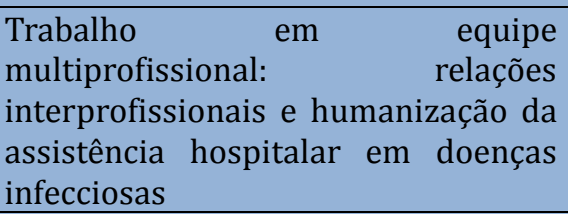 & $\begin{array}{l}\text { Cardoso } 21 / \\
2010\end{array}$ \\
\hline $\begin{array}{l}\text { A contribuição do acolhimento e do } \\
\text { vínculo na humanização da prática } \\
\text { do cirurgião-dentista no programa } \\
\text { saúde da família. }\end{array}$ & $\begin{array}{l}\text { Pinheiro e } \\
\text { Oliveira } 22 / \\
2011\end{array}$ \\
\hline $\begin{array}{l}\text { Cinco anos da Política Nacional de } \\
\text { Humanização: trajetória de uma } \\
\text { Política Pública }\end{array}$ & $\begin{array}{l}\text { Pasche, } \\
\text { Passo e } \\
\text { Hennington } \\
\text { 23/2011 } \\
\end{array}$ \\
\hline
\end{tabular}

organizada por meio de uma serie de dispositivos como Grupo de Trabalho de Humanização (GTH), constituído de representantes da instituição com o objetivo de implantar as diretrizes desta política: Contratos internos de gestão, firmados entre os serviços de saúde e as instâncias que representam outros níveis hierárquicos do SUS; Câmara Técnica de Humanização Fórum proposto para agregar instâncias/serviços/sujeitos com o objetivo de compartilhar experiências do/no campo de políticas/ações de humanização; Ouvidoria, que faz a escuta de usuários e trabalhadores; Colegiados Gestores Institucionais que têm como objetivo elaborar o plano diretor e sistemática de avaliação das ações de humanização 1,15,25.

A PNH se expressa como uma oferta metodológica, sendo caracterizada pela Tríplice Inclusão: dos diferentes sujeitos envolvidos no processo de produção em saúde; da perturbação que esta inclusão induz na gestão e nos processos de cuidar e a inclusão dos coletivos que se formam e consolidam a partir das duas inclusões anteriores ${ }^{23}$.

Estudos realizados sobre essa temática apresentam a humanização enquanto um diferencial competitivo e de qualidade, voltado para a lógica do mercado consumidor, pois as práticas gerenciais e os programas de humanização são adotados como ferramentas para fazer a diferença nos serviços em virtude da complexa exigência do mercado consumidor. Os profissionais de saúde também são convidados a desenvolver uma visão empreendedora do cuidado.

Associa se a este cenário o ambiente físico e da hotelaria hospitalar como fator de aumento na confiança, autoestima e bem estar dos pacientes, o que indica a necessidade de investimentos na hotelaria hospitalar e capacitação dos colaboradores como estratégia para melhoria na percepção do paciente, resultando em crescimento da empresa ${ }^{17,20 .}$.

Enquanto política pública a $\mathrm{PNH}$ busca um atendimento humanizado em todos os níveis de atenção. No âmbito da 
atenção primária em saúde alguns princípios são de origem recente, sendo ainda novidades nos serviços, o que causa "pontos de tensão" e necessidade de uma melhor compreensão para sua efetiva implantação nas unidades de saúde 22 .

Foram evidenciados impactos positivos na implantação da sistemática de autogestão alinhada com os princípios da PNH destacando a humanização como determinante de melhora no atendimento na unidade, melhoria na velocidade e qualidade frente aos diversos problemas dos usuários, pela maior autonomia dos funcionários, observando a melhor identificação e priorização de riscos/gravidade dos casos, com soluções para os usuários ${ }^{25}$.

As pesquisas realizadas nos serviços hospitalares relatam dificuldades similares encontradas na área de atenção primária: queixas contra o trabalho hegemônico e centralizador, questões precarizantes e a predominância do modelo biomédico que inviabiliza a implantação dos dispositivos da $\mathrm{PNH}^{3,19}$.

Na perspectiva de avaliação das ações propostas pela PNH é observada a dificuldade em propor indicadores para avaliar as ações humanizantes ${ }^{18}$. Faz se necessário propor indicadores que possam provocar reflexões sobre as representações sociais das estratégias humanizadoras frente aos sujeitos envolvidos nesse processo, visto que esses indicadores são subjetivos.

\section{Percepções sobre a humanização}

A percepção é um conceito complexo, diretamente relacionado às expectativas e experiências vivenciadas com a doença e o atendimento em saúde. Nesse aspecto a comunicação eficiente é tida como um dos requisitos para atingir uma pratica humanizada e integral da assistência. Usuários e trabalhadores relatam distintas opiniões sobre o que é humanização em saúde ${ }^{26}, 27$. As produções desta categoria estão no Quadro 3.
Quadro 3. Percepções sob a humanização e aspectos relacionais entre usuários, trabalhadores e gestores. Brasil, 2013.

\begin{tabular}{|c|c|}
\hline \multicolumn{2}{|c|}{$\begin{array}{l}\text { Categoria } 3 \text { - Percepções sob a humanização e } \\
\text { aspectos relacionais entre usuários, } \\
\text { trabalhadores e gestores. }\end{array}$} \\
\hline Publicações selecionadas & Autores \\
\hline $\begin{array}{l}\text { O Grupo de Trabalho de } \\
\text { Humanização e a humanização } \\
\text { da assistência hospitalar: } \\
\text { percepção de usuários, } \\
\text { profissionais e gestores }\end{array}$ & $\begin{array}{l}\text { Garcia, Argenta, } \\
\text { Sanchez e São } \\
\text { Thiago }^{4} / 2010\end{array}$ \\
\hline $\begin{array}{l}\text { Relações entre profissionais } \\
\text { de saúde e usuários durante } \\
\text { as práticas em saúde }\end{array}$ & $\begin{array}{l}\text { Schimith, Simon, } \\
\text { Brêtas e Budó }{ }^{26} \text { / } \\
2011\end{array}$ \\
\hline $\begin{array}{l}\text { A percepção da equipe de } \\
\text { saúde e do idoso hospitalizado } \\
\text { em relação ao cuidado } \\
\text { humanizado }\end{array}$ & $\begin{array}{l}\text { Martins et al. }{ }^{27} / \\
2008\end{array}$ \\
\hline $\begin{array}{l}\text { A humanização do trabalho } \\
\text { para os profissionais de } \\
\text { enfermagem }\end{array}$ & $\begin{array}{l}\text { Amestoy, } \\
\text { Schuwartz e } \\
\text { Thofehrn }^{28} / 2006 \\
\end{array}$ \\
\hline $\begin{array}{l}\text { A fraternidade em questão: } \\
\text { um olhar psicossociológico } \\
\text { sobre o cuidado e a } \\
\text { "humanização" das práticas de } \\
\text { saúde }\end{array}$ & Sá29/ 2009 \\
\hline $\begin{array}{l}\text { Humanização: a essência da } \\
\text { ação técnica e ética nas } \\
\text { práticas de saúde }\end{array}$ & $\operatorname{Rios}^{30} / 2009$ \\
\hline
\end{tabular}
elemento qualificador da transversalidade entre os sujeitos, diferentes áreas e projetos, contribuindo para a reorientação das práticas e um engajamento em um projeto institucional humanizante. Os processos de escutas recomendados pela $\mathrm{PNH}$ elevam o nível de satisfação dos clientes dos serviços de saúde ${ }^{17}$.

A humanização é a busca de uma relação pautada pelo respeito, na garantia dos direitos, na solidariedade, na ética, o que implica acolhimento, respeitando as necessidades dos usuários e trabalhadores na saúde. A responsabilidade dos gestores esta relacionada à alocação correta e ética dos recursos disponíveis e no cuidado essencial e digno baseado na solidariedade e cooperação entre todos os sujeitos envolvidos ${ }^{4,22}$.

A humanização está pautada na busca de uma relação guiada pelo respeito, na garantia dos direitos, na solidariedade, na ética, o que implica acolhimento, respeitando 
as necessidades dos usuários e trabalhadores na saúde. A responsabilidade dos gestores não somente para o controle dos gastos, mas para com os outros: A responsabilidade para com o outro é a essência do cuidado, solidariedade e cooperação ${ }^{4,29}$.

Em determinados níveis de atenção, como no ambiente hospitalar, as ações de humanização são enfatizadas na figura dos clientes, evidenciando a pouca atenção ao eixo sujeito-trabalho. A inclusão dos trabalhadores nas ações de humanização surge como resposta a um estado de tensão e insatisfação dos trabalhadores, uma vez que a internalização dos princípios humanizantes é fator preponderante para um ambiente mais humano e acolhedor para todos 29,30 .

Quanto ao foco dos estudos selecionados houve uma predominância de pesquisas que avaliaram a percepção ou satisfação dos usuários, trabalhadores de gestores sobre aspectos da $\mathrm{PNH}$, seguidos das reflexões teóricas e estudos que abordaram a temática no ambiente hospitalar. Acredita-se que a persistência em conhecer as opiniões dos atores envolvidos ocorreu devido ao fato da humanização ser um tema polissêmico, utilizado com diferentes sentidos e justificando diferentes práticas.

\section{CONCLUSÃO}

$\mathrm{O}$ impacto da $\mathrm{PNH}$ precisa ser melhor investigado e entendido, visto a complexidade do tema, como demonstram as publicações selecionadas. Os estudos assinalaram que a humanização nos serviços de saúde é um elemento essencial e determinante à melhoria na qualidade da assistência, satisfação dos usuários, condição para o sucesso de profissionais e estratégia de mercado para os serviços de saúde.

Os aspectos relacionais e as questões subjetivas se mostraram importantes para uma assistência humanizada. A relação pautada pelo respeito, na garantia dos direitos de usuários e trabalhadores, a comunicação eficiente, a ética e a participação de usuários, trabalhadores e gestores se colocaram como requisitos para a implantação da PNH enquanto uma política pública que atenda as demandas da sociedade.

Espera-se, com este estudo, estimular a realização de novas pesquisas sobre os impactos da implantação Política Nacional de Humanização da atenção e gestão nos serviços, utilizando teorias e desenhos metodológicos que contribuam para o entendimento das diretrizes da $\mathrm{PNH}$ em consonância com os princípios do SUS como a universalidade do acesso, participação e o direito ao cuidado.

A partir dos estudos selecionados foi possível observar que PNH oferece uma serie de ferramentas e instrumentos às instituições de saúde enquanto ambiente promotor de melhoria de qualidade de vida. Vale ressaltar que essas ferramentas não se limitam as alterações do espaço físico nos estabelecimentos de saúde ou mudança na postura dos profissionais, mas depende de uma organização multidisciplinar e disposição para a reflexão sobre as práticas, o que pode melhorar a eficácia no atendimento ao usuário.

Por meio desse estudo se pode perceber que a $\mathrm{PNH}$ não se apresenta como um programa pontual, mas como uma política publica, tomando como diretrizes o acolhimento, a ampliação da clínica, a gestão democrática, a valorização do trabalhador e a garantia dos direitos dos usuários, oferecendo estratégias de como produzir 0 cuidado em saúde, em todas as dimensões, sendo assim um marco de referencia para a construção de praticas de saúde que respeitem o cidadão e eleve a qualidade dos serviços.

\section{REFERÊNCIAS}

1. Ministério da Saúde (Br). Secretaria de Atenção à Saúde. Núcleo Técnico da Política Nacional de Humanização. HumanizaSUS: Política Nacional de Humanização: a humanização como eixo norteador das práticas de atenção e gestão em todas as instâncias do SUS. Série B. Textos Básicos de 
Saúde, Brasilia (DF): Editora do Ministério da Saúde, 2009.

2. Santos Filho SB, Figueiredo VON. Contratos internos de gestão no contexto da Política de Humanização: experimentando uma metodologia no referencial da cogestão. Interface comun. saúde educ. [online]. 2009; 13(1):615-26 [citado 20-06-2013]. Disponível em:

http://www.scielo.br/scielo.php?script=sci_ar ttext\&pid=S1414-

$32832009000500013 \& \operatorname{lng}=$ pt\&nrm=iso\&tlng= pt

3. Alves CA, Deslandes SF, Mitre RMDA. A gestão do processo de trabalho da enfermagem em uma enfermaria pediátrica de média e alta complexidade: uma discussão sobre cogestão e humanização. Interface comun. saúde educ. [online] 2011; 15(37):35161. [citado 20-06-2013]. Disponível em: <http://www.scielo.br/scielo.php?script=sci_a rttext\&pid=S1414-32832011000200003>.

4. Garcia AV, Argenta CL, Sanches KC, São Thiago ML. et al. O grupo de trabalho de humanização e a humanização da assistência hospitalar: percepção de usuários, profissionais e gestores. Physis (Rio J.). 2010; 20(3):811-34. [citado 20-06-2013]. Disponível em:

<http://www.scielo.br/scielo.php?script=sci_a rttext\&pid=S0103-73312010000300007>.

5. Mendes KDS, Silveira RCCP, Galvão CM. Revisão integrativa: método de pesquisa para a incorporação de evidências na saúde e na enfermagem. Texto e contexto enferm. [online]. 2008; 17(4):758-64 [citado 21-072013] Disponível em: <http://www.scielo.br/scielo.php?script=sci_a rttext\&pid=S010407072008000400018>

6. Lima MFDS. Das práticas espontâneas à receita de humanização: um estudo sobre a implementação da Política Nacional de Humanização em um hospital do Rio de Janeiro. Dissertação (Mestrado em Saúde Coletiva) - Instituto Medicina Social da Universidade do Estado do Rio de Janeiro, 2007.

7. Carvalho CAP, Marsicano JA, Carvalho FS, Sales-Peres A, Bastos JCM, Sales-Peres SHC. Acolhimento aos usuários: uma revisão sistemática do atendimento no Sistema Único de Saúde. Arq. ciênc. saúde. [online]. 2008;
15(2):92-5 [citado 22-06-2013]. Disponível em: http://www.cienciasdasaude.famerp.br/racs ol/vol-15-2/iD\%20253.pdf>.

8. Guedes CR, Pitombo LB, Barros MEBD. Os processos de formação na Política Nacional de Humanização: a experiência de um curso para gestores e trabalhadores da atenção básica em saúde. Physis. 2009; 19(4):1087-109. [citado 20-06-2013].

Disponível em:<http://www.scielo.br/scielo.php?script=s ci_arttext\&pid=S0103-73312009000400010>. 9. Paulon SM, Carneiro MLF. A educação a distância como dispositivo de fomento às redes de cuidado em saúde. Interface comun. saúde educ. [online]. 2009; 13(1 Supl.1):74957. [online]. [citado20-06-2013]. Disponível em:

<http://www.scielo.br/scielo.php?script=sci_a rttext\&pid=S1414-32832009000500026

10. Scholze ADSS, Duarte Junior CF, Silva YFE. Trabalho em saúde e a implantação do acolhimento na atenção primária à saúde: afeto, empatia ou alteridade? Interface comun saúde educ. [online]. 2009; 13(31):303-14.

11. Blasco PG. É possível humanizar a Medicina? Reflexões a propósito do uso do Cinema na Educação Médica. Mundo da saúde. 2010; 34(3):357-67. [citado 22-06-2013]. Disponível em: <http://www.saocamilosp.br/pdf/mundo_saude/77/357a367.pdf>

12. Nascimento ERP, Hilsendeger BR, Neth C, Belaver GM, Bertoncello KCG. Classificação de risco na emergência: avaliação da equipe de enfermagem. Rev. enferm. UERJ [online]. 2011; 19(1):84-8. [citado 22-06-2013]. Disponível em:

<http://www.facenf.uerj.br/v19n1/v19n1a14. pdf>.

13. Pimentel ADF, Barbosa RM, Chagas MA. Musicoterapia na sala de espera de uma unidade básica de saúde: assistência, autonomia e protagonismo. Interface comun. saúde educ. [online] 2011; 15(38):741-54. [citado 20-06-2013]. Disponível em: <http://www.scielo.br/scielo.php?script=sci_a rttext\&pid=S1414-32832011000300010>. $>$.

14. Trentini M, Paim L, Vásquez ML. A responsabilidade social da enfermagem frente à política da humanização em saúde. Colomb. Med. 2011; 42(supl.1):95-102. [citado 22-06- 
2013]. Disponível em: <http://colombiamedica.univalle.edu.co/index .php/comedica/article/view/825/1367>

15. Silveira MDGG, Baldacci ER. Humanização e autogestão em uma unidade básica de saúde. Pediatria (Säo Paulo). 2006; 28(4):226-33.

16. Coelho BP. 0 reencantamento do concreto e as apostas nas mudanças nos modelos de atenção e de gestão do SUS (o caso do Instituto Hospitalar General Edson Ramalho/João Pessoa/Paraíba). [dissertação de mestrado]. Recife (PE): Fundação Osvaldo Cruz/Fiocruz;2006. 82p.

17. Backes DS, Silva DM, Siqueira HH, Erdmann AL. O produto do serviço de enfermagem na perspectiva da gerência da qualidade. Rev. gaúch. enferm. 2007; 28(2):163-70. [citado 2006-2013]. Disponível em: <http://www.seer.ufrgs.br/index.php/Revista GauchadeEnfermagem/article/view/3159/17 30>.

18. Santos-Filho SB. Perspectivas da avaliação na Política Nacional de Humanização em Saúde: aspectos conceituais e metodológicos. Ciênc. saúde coletiva [online]. 2007; 12(4): 999-1010 [citado 22-06-2013]. Disponível em: $\quad<$ http://dx.doi.org/10.1590/S141381232007000400021>.

19. Trad LAB, Esperidião MA. Gestão participativa e corresponsabilidade em saúde: limites e possibilidades no âmbito da Estratégia de Saúde da Família. Interface comun saúde educ. [online]. 2009; 13(supl.1):557-70. [citado 21-06-2013]. Disponível em: http://www.scielo.br/scielo.php?script=sci_ar ttext\&pid=S1414-

32832009000500008\&lng=es.

http://dx.doi.org/10.1590/S1414-

32832009000500008.

20. Pinochet LHC, Galvão CR. Aspectos humanos na gestão hospitalar: revisão. Mundo da saúde. 2010; 34(4):498-507.

21. Cardoso CG. Trabalho em equipe multiprofissional: relações interprofissionais e humanização da assistência hospitalar em doenças infecciosas. [dissertação de mestrado]. Rio de Janeiro (RJ): Escola Nacional de Saúde Sergio Arouca; 2010. 186p.

22. Pinheiro PM, Oliveira LCD. A contribuição do acolhimento e do vínculo na humanização da prática do cirurgião-dentista no Programa de Saúde da Família. Interface comun saúde educ. [online]. 2011; 15(36):185-98.

23. Pasche DF, Passos E, Hennington ÉA. Cinco anos da Política Nacional de Humanização: trajetória de uma política pública. Ciênc saúde coletiva [online]. 2011; 16(11):4541-8.

24. Ministerio da Saúde(Br). Secretaria de Atenção à Saúde. Núcleo Técnico da Política Nacional de Humanização. HumanizaSUS: documento base para gestores e trabalhadores do SUS. Série B. Textos Básicos de Saúde, Brasilia (DF). Editora Ministério da Saúde, 2006.

25. Ministério da Saúde (Br). Secretaria de Atenção à Saúde. Núcleo Técnico da Política Nacional de Humanização. Acolhimento e classificação de risco nos serviços de urgência. Brasília (DF): Editora do Ministério da Saúde, 2009.

26. Schimith MD, Simon BS, Brêtas ACP, Budó MDLB. Relações entre profissionais de saúde e usuários durante as práticas em saúde. Trab educ. saúde. 2011; 9(3):479-503.

27. Martins et. al. A percepção da equipe de saúde e do idoso hospitalizado em relação ao cuidado humanizado. ACM arq. catarin. med. 2008; 37(1):30-7.

28. Amestoy SC, Schuwartz E, Thofehrn MB. A humanização do trabalho para os profissionais de enfermagem. Acta paul. enferm. 2006; 19(4):444-9.

29. Sá MDC. A fraternidade em questão: um olhar psicossociológico sobre o cuidado e a "humanização" das práticas de saúde. Interface comun saúde educ. [online]. 2009; 13(supl.1): 651-64.

30. Rios IC. Humanização: a essência da ação técnica e ética nas práticas de saúde. Rev. bras. educ. méd. 2009; 33(2):253-61.

\section{CONTRIBUIÇÕES}

Delvane José de Souza desenhou o estudo, realizou a coleta e análise dos artigos, bem como a redação do manuscrito;

Divanice Contim colaborou com a redação e formatação da revisão de texto;

Maria D'Innocenzo colaborou com a análise dos artigos selecionados e participou da revisão crítica do manuscrito. 